\title{
Vision problems following stroke: Developing a Best Practice Statement
}

\begin{abstract}
An estimated 15 million people worldwide suffer a stroke each year and, in developed countries, survival is increasing. Of those who survive 30 days or more after their first event, many experience stroke-related vision and visual problems. Although screening for such problems after diagnosis of stroke is recommended, no standard method for complying with this recommendation is available. As visual problems are not always recognised by the sufferer, or obvious to others, they can be overlooked. Undetected problems result in distress to the individual and the people important to them, and may result in longer stays in hospital or repeat admissions. Health professionals in the acute care setting need to be aware that there is a risk of visual problems after stroke and have access to best practice guidance for screening, assessment and management of stroke-related visual problems. This paper describes the process used by a multidisciplinary team to develop a best practice statement for screening, assessment and management of vision problems during the acute phase of stroke.
\end{abstract}

Key Words: Acute Stroke, Stroke management, Vision, Screening. Best Practice,

\section{Introduction}

It is estimated that, each year, 15 million people suffer a stroke. Of those who survive, 5 million are left with a permanent disability (World Heart Federation 2014) In 2012, 12,500 new cases of stroke were reported in Scotland (National Health Service Information Statistics Division (NHS ISD), 2012)). The percentage of people surviving stroke $\geq 30$ days following their first emergency admission to hospital rose by almost $4 \%$ (80.2\% to $84.0 \%$ ) between $2003 / 2004$ and $2012 / 2013$. Thirty day survival in those $\geq$ 75 years of age has risen by almost 4\% (74.2\% to $77.9 \%)$ (NHS ISD 2014). Associated brain damage in survivors can be extensive and may include visual perception problems, eye movement disorders, low vision and visual field loss (Rowe et al 2009). These impose an additional burden on the sufferer and are particularly problematic for those who have co-existing disease or disability.

In 2012/2013, UK guidelines recommended that everyone who suffered a stroke should be screened for vision problems (SIGN 118, National Institute for Healthcare and Excellence [NICE CG68, 2008, NICE CG162, 2013], Royal College of Physicians 
(RCP 2012)). As yet, no standardised approach to vision screening, or for management of identified visual problems is available for patients in the acute phase of stroke. In addition, the best course of rehabilitation remains unknown. Moreover, although support services are available, stroke survivors report that they are rarely directed to them. These factors can adversely affect recovery and rehabilitation and negatively impact on the quality of life of the sufferer and their family (Bambara et al 2009, Tistad et al 2012).

In 2012, the Scottish Vision and Stroke Network proposed that a Best Practice Statement (BPS) be developed to help address these issues. The proposed work was funded by the National Advisory Committee for Stroke (NACS) in Scotland and subsequently undertaken by a multi-disciplinary team of clinicians, academics, voluntary organisations, and patient representatives from across Scotland.

\section{Aim}

The project aimed to identify best practice for screening, assessment and management of vision problems for adults admitted to hospital with a diagnosis of acute stroke, and to disseminate the results of this work.

\section{Method}

The method used to develop the statement was adapted from one reportedly developed by NHS Quality Improvement Scotland - now Health Improvement Scotland (NHS HIS). This comprised the formation of a multidisciplinary steering group, the conduct of a rapid evidence assessment (REA) and subsequent formation of a project working group and critical reading group. The key steps in the process are outlined in Figure 1.

\section{Rapid Evidence Assessment}

The REA approach applies a well-defined search strategy to a range of databases to identify a circumscribed body of relevant literature. The search was narrowed to answer, identify, review, and select literature relating to specific and clearly defined questions. The timescale for completion was restricted to a maximum of 6 months. 


\section{The Steering Group}

The steering group determined the scope of the project, proposed membership of the other groups, and defined the four topics for investigation:

1. Initial screening on presentation in hospital.

2. Visual field deficits.

3. Eye movement disorders.

4. Visual inattention/neglect.

Two patients with stroke-related vision problems contributed to the project by providing information and suggestions for the content of the final document.

\section{Literature Search Strategy}

The search strategy (Table 1) was conducted by the project research assistant (JS).

The priorities for the literature search were to:

- Identify empirical research;

- Identify literature reviews and systematic reviews;

- $\quad$ Identify grey literature.

Only articles published in the English language were reviewed. Literature relating to paediatric care and rehabilitative techniques for chronic stroke were excluded.

\section{Search Results}

The initial search returned over 9,041 references. Of these, 234 met the eligibility criteria and were reviewed by the Working Group; 118 were used to develop the statement (Figure 2).

\section{The Working Group}

The multi-disciplinary working group comprised academics; NHS healthcare professionals; and representatives from relevant voluntary organisations from across Scotland. The group met face to face on two occasions, with smaller subgroups meetings face to face or virtually as required, in order to review identified literature and to reach consensus about the quality of the papers reviewed. In preparation for the first meeting, members completed a short questionnaire to 
confirm their previous review experience and area of expertise. This helped identify membership of the four smaller teams which subsequently focussed on one of the four topics previously identified. Each of these small groups comprised 4-6 members with combined expertise in stroke care, the relevant group topic, and previous review experience. A copy of the Critical Appraisal Skills Programme critical appraisal tools (CASP UK), and an adapted SIGN Considered Judgement Proforma (SIGN 2012) was provided to each group. Groups were self-directed in their review of the selected literature and in producing the draft statement relevant to their topic which was subsequently reviewed by the Critical Reading Group.

\section{The Critical Reading Group}

Following review of the draft statements, the critical reading group provided written feedback on the content of the four topic statements with a particular focus on the topic most relevant to their area of expertise. Suggested revisions were relayed to the smaller working groups. Following discussion, a consensus was reached and revisions made where appropriate.

\section{Consultation and Dissemination}

The penultimate draft of the combined topic statements was circulated to individuals and organisations with a particular interest and/or involvement in stroke and vision problems across Scotland. Following consultation, and appropriate revision, the best practice statement for vision problems following acute stroke was published with a separate summary statement outlining the key points (University of Glasgow 2013a, 2013b) and subsequently disseminated by contributors and colleagues.

\section{Discussion and Conclusion}

The production of the BPS and summary statement described in this article was the result of the collaborative efforts of a multi-disciplinary team of health professionals, academics, voluntary organisations and stroke sufferers who combined their expertise and knowledge to produce and disseminate the outcomes of their work. The review highlighted that the evidence base relating to the four identified topics is poor. The guidance provide in the final documents is based on the best available evidence at the time of publication; primarily: good clinical practice, clinical expertise, and patient experience. It is recommended that additional good quality 
research be conducted and the results implemented and evaluated enabling the contents of the document to be updated with current and robust evidence.

\section{Acknowledgements}

We would like to thank everyone who contributed to the development of the best practice statement for screening, assessment, and management of vision Problems in the first 30 days after an acute stroke. It would not have been completed without their combined knowledge, experience, support and enthusiasm.

The authors declare they have no vested interests. Funding for the project was provided by the National Advisory Committee for Stroke in Scotland.

\section{References}

Bambara, J.K., Wadley, V., Owsley. C., Martin, R.C., Porter, C \& Dreer, L.E. (2009) Family functioning and low vision: A Systematic Review. Journal of Visual Impairment and Blindness. 103 (3): 137-149.

University of Glasgow 2013a. Best Practice Statement, September 2013, Screening, assessment and management of vision problems in the first 30 days after an acute stroke. University of Glasgow 2013 http://www.gla.ac.uk/media/media 218721 en.pdf

University of Glasgow 2013b. Summary of a Best Practice Statement for screening, assessment and management of vision problems in the first 30 days after an acute stroke. http://www.gla.ac.uk/media/media_292336_en.pdf

Critical Appraisal Skills Programme (CASP) Checklists http://www.caspuk.net/\#!casp-tools-checklists/c18f8 Last accessed December 2014. Summary of a Best Practice Statement for screening, assessment and management of vision problems in the first 30 days after an acute stroke.

NHS ISD 2012. Stroke Statistics Update http://www.isdscotland.org/HealthTopics/Stroke/Publications/2012-12-18/2012-12-18 StrokeReport.pdf?42957705260. Last viewed 11.09.2013.

NICE CG68 2008 Stroke: Diagnosis and initial management of acute stroke and transient ischaemic attack (TIA) http://www.nice.org.uk/guidance/cg68/chapter/guidance Last viewed 02.08.2013. Summary of a Best Practice Statement for screening, assessment and management of vision problems in the first 30 days after an acute stroke. Scottish Intercollegiate Guidelines Network, SIGN 50, A Guideline developer's handbook, Considered Judgement proforma 2012 http://www.sign.ac.uk/methodology/checklists.html 
NICE CG162, 2013. Stroke Rehabilitation: Long-term Rehabilitation After Stroke. Nice Clinical Guideline 162.

http://www.nice.org.uk/nicemedia/live/14182/64098/64098.pdf. Last viewed 02.08.2013.

Rowe, F., Brand, D. Jackson, C. A., Price, A., Walker, L., Harrison, S. et al. (2009). Visual impairment following stroke: do stroke patients require vision assessment? Age \& Ageing, 38(2), 188-193.

Royal College of Physicians 2012. National Clinical Guidelines for Stroke. Fourth Edition. http://www.rcplondon.ac.uk/sites/default/files/national-clinical-guidelines-forstroke-fourth-edition.pdf . Last viewed 02.08.2013

SIGN 118, 2010. Management of Patients with Stroke: Rehabilitation, Prevention and Management of Complications, and Discharge Planning. A National Clinical Guidelines. http://www.sign.ac.uk/pdf/sign118.pdf. Last viewed 02.08.2013

Tistad, M., Tham. K., von Kock, L., \& Ytterberg, C. (2012). Unfulfilled rehabilitation needs and dissatisfaction with care 12 months after a stroke: An explorative observational study. BioMedCentral Neurology. 12: 40. 1-7.

World Heart Federation 2014 http://www.world-heart-federation.org/cardiovascular- 
Table 1: Databases and Search Terms

\begin{tabular}{|c|c|}
\hline Databases & Search Terms (combined) \\
\hline $\begin{array}{l}\text { Electronic database } 2000 \text { to } 2013 \\
\text { - The Cochrane Library, } \\
\text { - CINAHL, } \\
\text { - EMBASE, } \\
\text { - Medline, } \\
\text { - PsycINFO, } \\
\text { Hand Seb of Science } \\
\text { - The British and Irish Orthoptic } \\
\text { Journal }\end{array}$ & $\begin{array}{l}\text { adaptation agnosia assessment } \\
\text { cancellation task, Charles Bonnet } \\
\text { clinical examination, conjugate eye } \\
\text { deviation, diplopia, depth perception } \\
\text { extinction, eye movement disorder } \\
\text { gaze palsy } \\
\text { hemianopsia, hemianopia, hemianopic } \\
\text { inattention } \\
\text { line bisection, low vison } \\
\text { nystagmus } \\
\text { ocular Icranial nerve palsy, } \\
\text { mobility disorder, motility } \\
\text { optic ataxia, oscillopsia } \\
\text { patching, perceptual disorders, prism } \\
\text { adaptation, saccade, scanning, } \\
\text { screening, scotoma } \\
\text { squint, stroke, subarachnoid } \\
\text { haemorrhage, strabismus } \\
\text { visual/field, field deficit, field loss } \\
\text { enlargement, hallucination, pathway } \\
\text { perception, restoration therapy } \\
\text { vestibular ocular reflex }\end{array}$ \\
\hline
\end{tabular}


Research Assistant appointed $\downarrow$

- Conduct systematic search of literature

- Screen literature and select papers to be sent to working group based on inclusion/exclusion criteria

- Source grey literature

- Ascertain current policy and legislation

- Seek advice from third sector and other relevant sources

Publish and disseminate BPS

BPS revised in response to feedback from critical reading group

BPS circulated to consultation group
Scottish Vision and Stroke Network scope area and decide on topic to be investigated

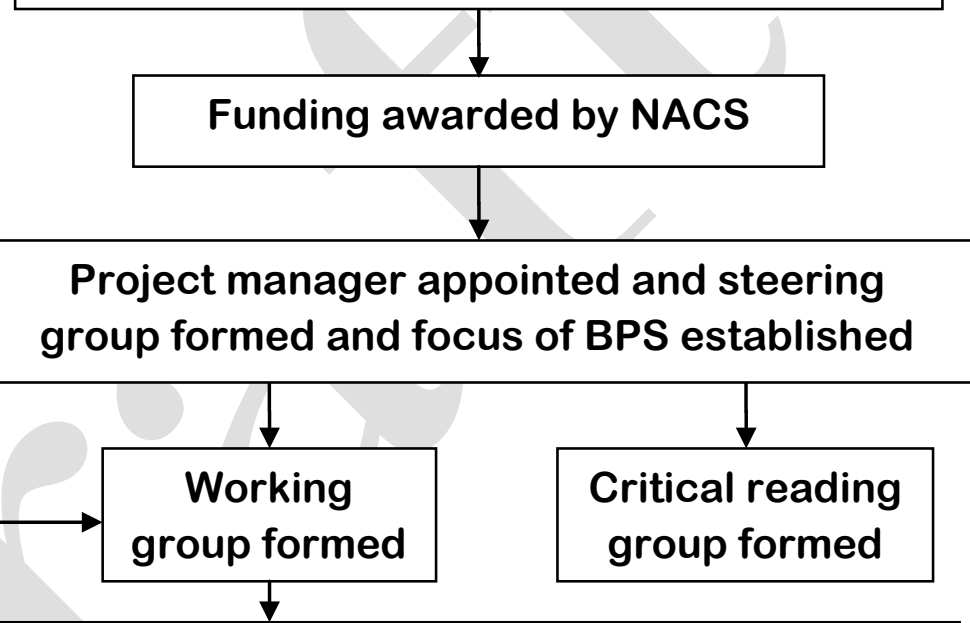

- Review literature for relevance to clinical practice

- Develop statements to be included in BPS

- Incorporate patients views into BPS

- Use experience from clinical practice to make recommendations where evidence is missing

Drafted document sent to working group

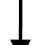

Revised draft sent to critical reading group 
Figure 2: Results of the literature search

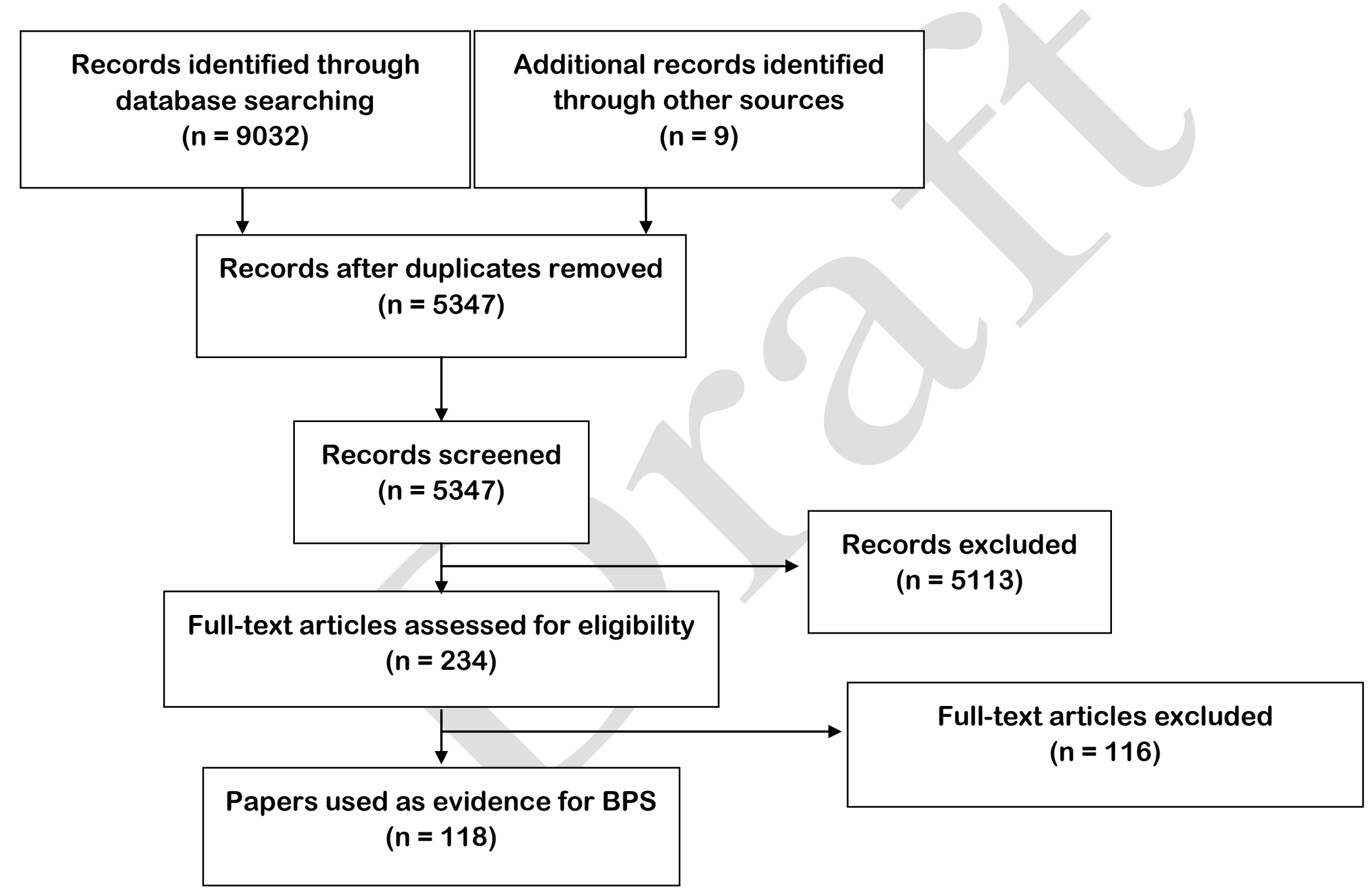




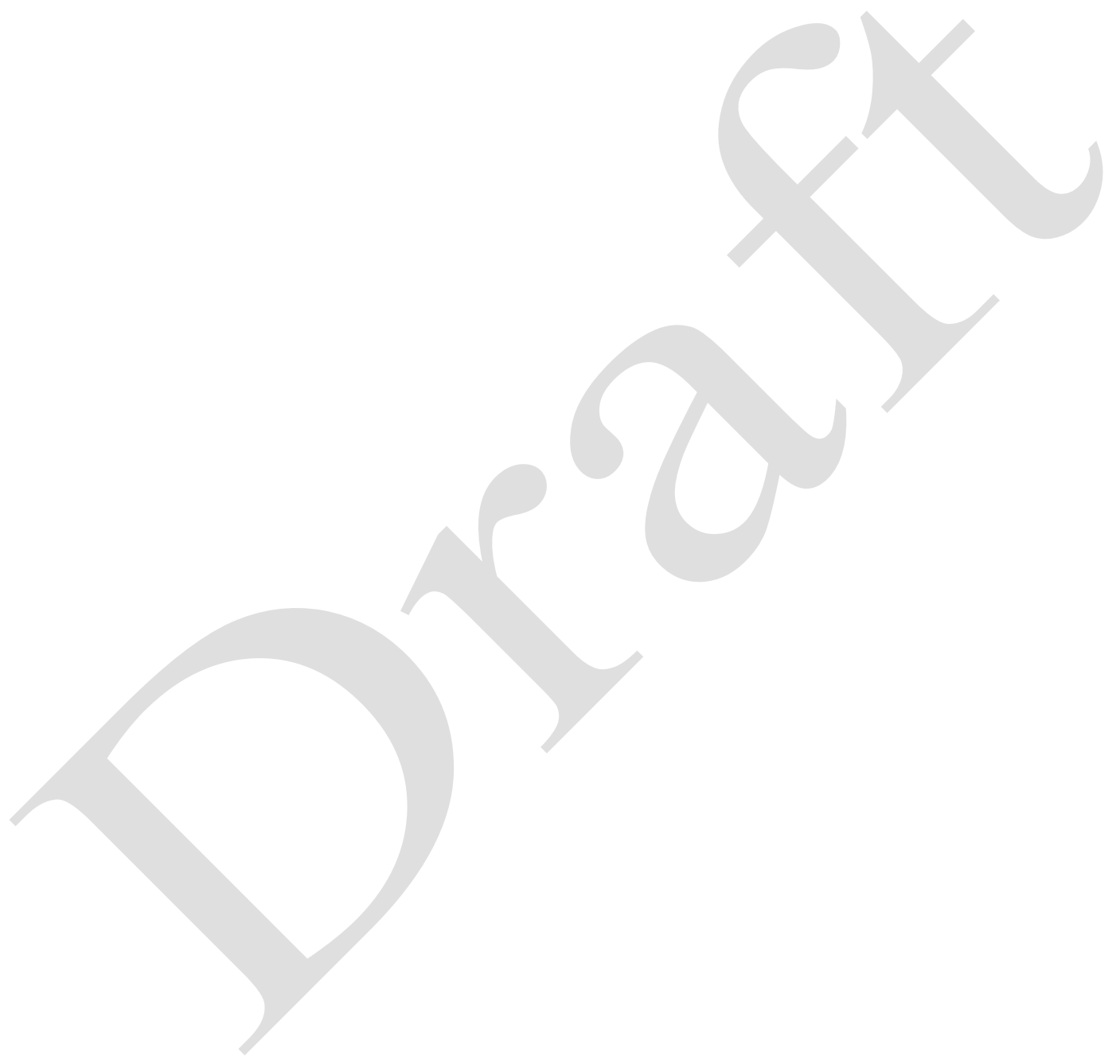

